\title{
The Sleeping Pill Prescription Rate for Inpatients at a General Hospital
}

\author{
Soyoung Youn, MD, Chi-Won C. Hann, BA, Boram Park, MD, Suyeon Lee, MD, Changnam Kim, MD, \\ Kikyoung Yi, MD, Seockhoon Chung, MD, PhD \\ Department of Psychiatry, Asan Medical Center, University of Ulsan College of Medicine, Seoul, Korea
}

Background and Objective Hospitalized patients often suffer from sleep disturbance. Impaired sleep for inpatients is a multifactorial phenomenon, comprised of medical, environmental, and behavioral influences imposed by hospitalization. In such situation, inpatients are frequently prescribed sleeping pills. The aim of this study was to explore the pattern of sleeping pill prescription for hospitalized patients in a general hospital.

Methods Located in Seoul, Korea, Asan Medical Center is a general hospital that oversees about 2100 to 2300 inpatients per day. We estimated the proportion of patients who were prescribed sleeping pills at admission and discharge from the hospital, excluding pediatric care units. In addition, we quantified the number of patients taking prescribed sleeping pills on the first day of each month of 2014.

Results Among 118475 patients admitted to Asan Medical Center in 2014, 4205 (3.54\%) were taking sleeping pills at the time of admission. In addition, 4652 (3.93\%) patients were prescribed sleeping pills as a discharge medication, of which 2256 (1.90\%) initiated hypnotics intake during hospital stay. Surveyed on the first day of every month of $2014,7.3 \%$ to $10.0 \%$ of inpatients were observed to be taking sleeping pills.

Conclusions The number of prescriptions of sleeping pills was found to increase with hospital stay. A palpable need for sleep hygiene education and the implementation of a hypnotics reduction program for inpatients is warranted.

Sleep Med Res 2016;7(1):33-38

Key Words Hypnotics, Inpatients, Insomnia, Sleep.

Received: June 7, 2016

Revised: June 13, 2016

Accepted: June 14, 2016

Correspondence

Seockhoon Chung, MD, PhD

Department of Psychiatry,

Asan Medical Center,

University of Ulsan College of Medicine,

88 Olympic-ro 43-gil, Songpa-gu,

Seoul 05505, Korea

Tel +82-2-3010-3411

Fax +82-2-485-8381

E-mailsschung@amc.seoul.kr

\section{INTRODUCTION}

Insomnia is one of the most common complaints from inpatients in all departments. ${ }^{1,2}$ The ward environment can present multiple obstacles to inducing and maintaining sleep for inpatients. Alarming noise, harsh lighting, and clinical procedures such as blood sampling, diagnostic tests, checks of vital signs, and other therapeutic procedures that may take place at inoptimal times can disturb inpatients' sleep. ${ }^{3-8}$ In the intensive care unit, for instance, the mean number of care interactions per night has been reported to be over $400^{5,6}$ The multi-bed design of many hospitals also calls for sleep disturbance through involuntary contact with neighboring patients, ranging from snoring and delirium to routine noise coming from patients sharing the same room. ${ }^{9,10}$ Aside from environmental factors, symptoms associated with the patient's disease, low physical mobility under dimmed or low luminance place, and side effects of medications can also interfere with their circadian rhythms. ${ }^{11-13}$ Furthermore, the underlying illness that led to admission and the fact that patients are removed from domestic settings to be placed in an unfamiliar atmosphere may be distressing, adversely affecting sleep cycles. ${ }^{14}$

Fragmented or insufficient sleep may exacerbate existing medical conditions, lower threshold for pain perception, and set off emotional or affective imbalances such as depression and anxiety, which can feed back by disturbing sleep, creating a vicious cycle. ${ }^{13,15-17}$ As sleep deficiency considerably deters quality of life and can hinder efficient recovery from illness, ${ }^{2,18,19}$ addressing patients' sleep disturbance is crucial. Shadowed by somatic symptoms that com- 
prise the majority of physician interest, however, insomnia and complications related to sleep are often left unattended. Within the conventional system, doctors tend to quickly calm the inpatients' sleep complaints by prescribing sleeping pills prior to considerable evaluation or efforts to eliminate the triggering factors and alleviate patient misconception about sleep.

In fact, the hypnotics prescription rate among inpatients is known to be higher compared to the general population. Previous studies have shown that $1.5 \%$ and $3 \%$ of the general population take hypnotics, according to European data sets and the National Health and Nutrition Examination Survey, respectively. ${ }^{20,21}$ In South Korea, $1.47 \%$ of the general population was found to be under prescribed hypnotics when defining hypnotics as zolpidem or triazolam. ${ }^{22}$ In contrast, hospitalized patients constituted $26-27 \%$ of the national hypnotics prescription rate in Japan and the United States. ${ }^{23}$ Benzodiazepines and Z-class drugs are associated with multiple known side effects, such as drowsiness, impaired cognitive and motor performances, delirium, and increased risk of falling, driving accidents, or obstructive sleep apnea. ${ }^{24-27}$ Importantly, indiscriminate pre-

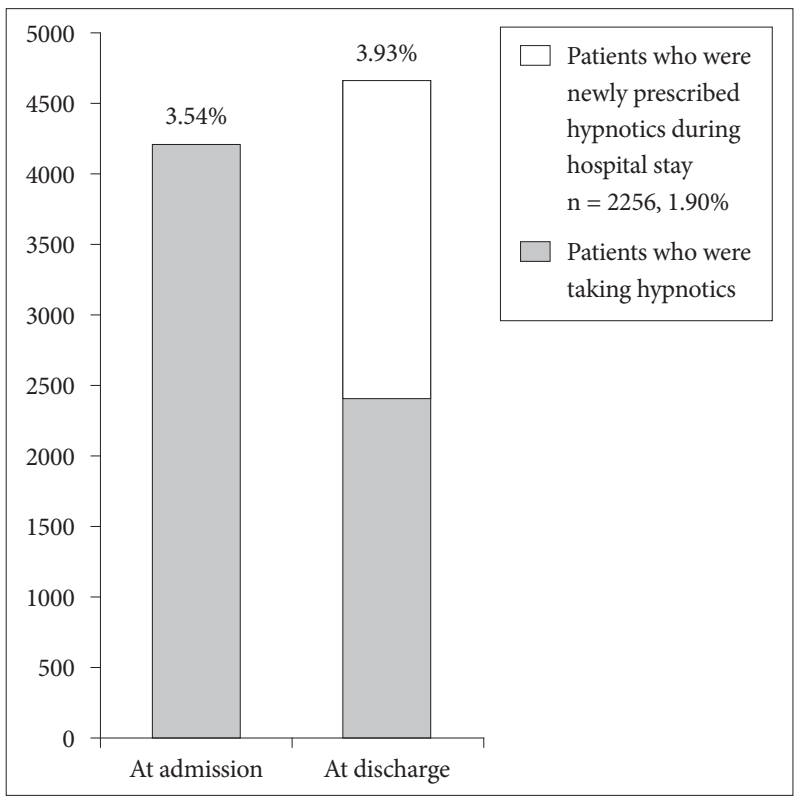

Fig. 1. The proportion of patients who were prescribed hypnotics at the time of admission or discharge among all patients admitted in 2014. scription of these drugs may result in long-term use and potentially lead to substance use disorders such as dependence and withdrawal. ${ }^{28-31}$ Therefore, there is significant effort to reduce the hypnotics prescription rate of inpatients. Several reseachers have reported the benefits of sleep-hygiene education and relaxation programs for hospitalized patients, demonstrating that the interventions are effective in reducing the prescription rates of sleeping pills. ${ }^{32-34}$

We hypothesized that the frequency of being prescribed sleeping pills would increase with hospital stay. Primary medical illnesses and patient emotional status can disturb sleep, and may lead to increased hypnotics prescription rates among hospitalized patients. The aim of this study was to investigate whether the rate of hypnotics prescription would increase with hospitalization in a general hospital and to quantify this change.

\section{METHODS}

We estimated the proportion of patients who were taking sleeping pills at the time of admission and at the time of discharge among all newly admitted patients in 2014. Pediatric care units were excluded. Using these data, we explored whether the hypnotics prescription rate increased with hospital stay. On the first day of each month, we also investigated the proportion of patients who were currently under prescription of any kind of sleeping pills. We classified sleeping pills as zolpidem immediate-release (IR) or extended-release (CR) form, triazolam, benzodiazepine including clonazepam and bromazepam, and trazodone, when these were administered to inpatients in the evening with the prescription code "hora somni (HS)". Zolpidem and triazolam were usually considered as sleeping pills in S. Korea. And among various benzodiazepine, clonazepam and bromazepam were frequently used as sleeping pills in our hospital.

Data was obtained from Asan Medical Center (Seoul, Korea), the largest single hospital in Korea. Over 110000 patients are admitted per year, and more than 2100 inpatients stay per day on 2715 licensed beds. Data in this study was driven from clinical and research sources in the hospital, and an honest broker provided it to researchers after de-identification. The study protocol was approved by the Institutional Review Board of Asan

Table 1. Inpatients who were prescribed sleeping pills at the time of admission or discharge

\begin{tabular}{|c|c|c|c|c|c|c|}
\hline & \multicolumn{4}{|c|}{1 tablet } & \multirow[b]{2}{*}{2 tablets } & \multirow[b]{2}{*}{$\geq 3$ tablets } \\
\hline & $\begin{array}{l}\text { Zolpidem } \\
\text { IR or CR }\end{array}$ & Triazolam & $\begin{array}{c}\text { Clonazepam or } \\
\text { bromazepam }\end{array}$ & Trazodone & & \\
\hline $\begin{array}{l}\text { At the time of admission } \\
(\mathrm{n}=4205,3.54 \%)\end{array}$ & $\begin{array}{c}2394 \\
(56.9 \%)\end{array}$ & $\begin{array}{c}209 \\
(5.0 \%)\end{array}$ & $\begin{array}{c}812 \\
(19.3 \%)\end{array}$ & $\begin{array}{c}188 \\
(4.5 \%)\end{array}$ & $\begin{array}{c}487 \\
(11.6 \%)\end{array}$ & $\begin{array}{c}115 \\
(2.7 \%)\end{array}$ \\
\hline $\begin{array}{l}\text { At the time of discharge } \\
(\mathrm{n}=4652,3.93 \%)\end{array}$ & $\begin{array}{c}2665 \\
(57.3 \%)\end{array}$ & $\begin{array}{c}257 \\
(5.5 \%)\end{array}$ & $\begin{array}{c}865 \\
(18.6 \%)\end{array}$ & $\begin{array}{c}220 \\
(4.7 \%)\end{array}$ & $\begin{array}{c}518 \\
(11.1 \%)\end{array}$ & $\begin{array}{c}127 \\
(2.7 \%)\end{array}$ \\
\hline
\end{tabular}

IR: immediate-release, CR: extended-release. 
Medical Center.

\section{RESULTS}

After excluding patients in pediatric care units, a total of 118475 patients were admitted to Asan Medical Center in 2014. Among the 4205 (3.54\%) inpatients who were already

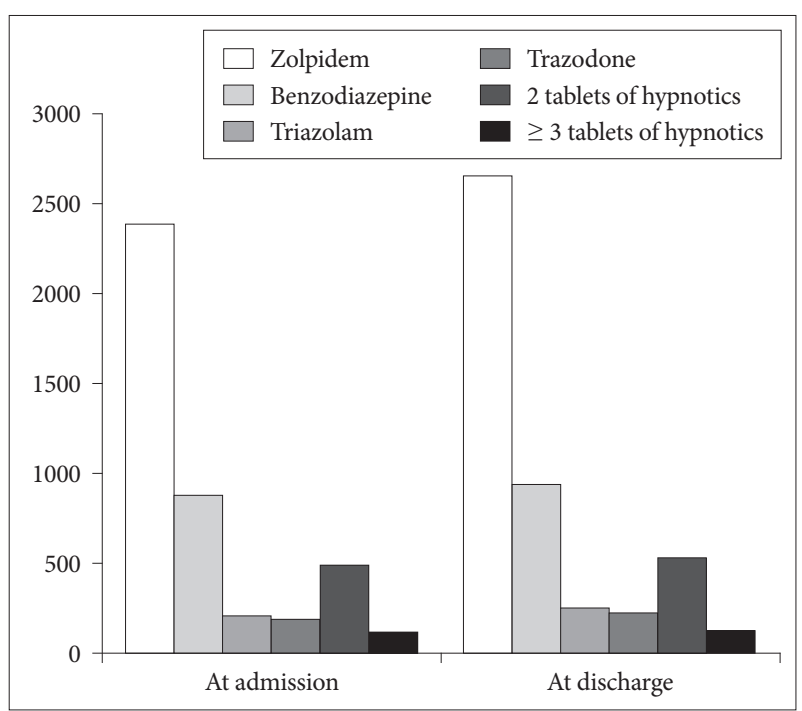

Fig. 2. Types of hypnotics the patients were taking at the time of admission and discharge. taking prescribed sleeping pills at the time of admission, 2396 (57.0\%) continued to take their pills at the time of discharge. Of all inpatients, 4652 (3.93\%) were taking prescribed sleeping pills at the time of discharge, of which 2256 (48.5\%) began their prescription post-admission (Fig. 1).

Among inpatients who were prescribed at least one table of sleeping pills at the time of admission, 56.9\% $(n=2394)$ were prescribed zolpidem IR or zolpidem CR, 19.3\% ( $n=812)$ were prescribed benzodiazepine including clonazepam or bromazepam, 5.0\% ( $\mathrm{n}=209)$ were prescribed triazolam, and 4.5\% $(\mathrm{n}=$ 188) were prescribed trazodone (Table 1). Among inpatients who were prescribed at least one tablet of hypnotics at the time of discharge, $57.3 \%(n=2665)$ were prescribed zolpidem, $18.6 \%$ $(\mathrm{n}=865)$ benzodiazepine including clonazepam and bromazepam, 5.5\% $(\mathrm{n}=257)$ triazolam, and $4.7 \%(\mathrm{n}=220)$ trazodone (Table 1, Fig. 2).

On the first day of every month in 2014, 7.3-10.0\% of inpatients were taking sleeping pills (Fig. 3). The most frequently prescribed hypnotics were zolpidem (42.8-55.6\%), benzodiazepines other than triazolam (12.8-25.8\%), triazolam (5.2-13.5\%), and trazodone (1.8-5.8\%) (Table 2). Two tablets of hypnotics were prescribed to $10.4-22.1 \%$, while over three tablets of hypnotics were prescribed to $1.1-6.7 \%$ of inpatients in 2014 .

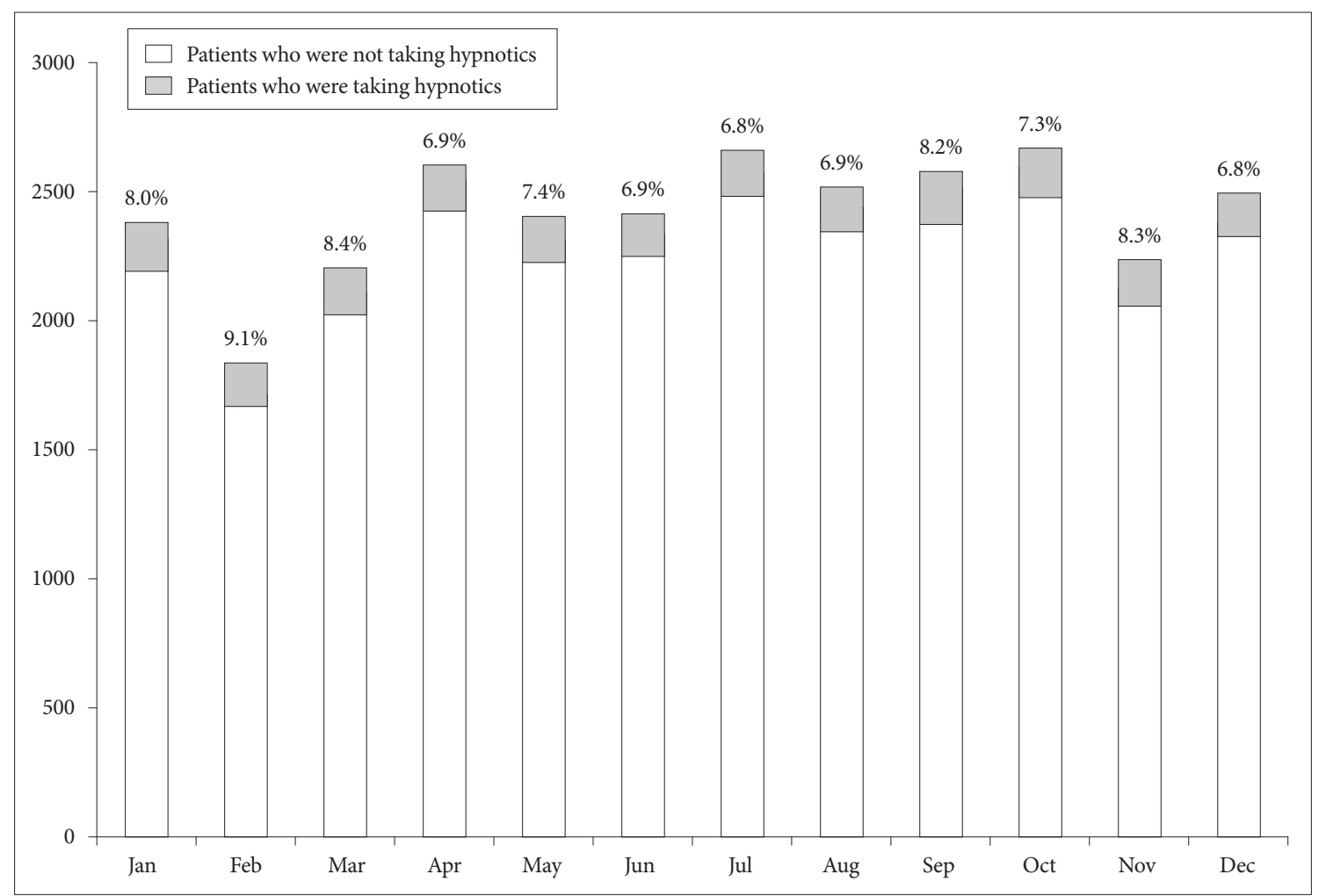

Fig. 3. The proportion of patients who were taking hypnotics among all inpatients when assessed on the first day of each month of 2014 . 
Table 2. Inpatients who were prescribed sleeping pills on every first day of each month of 2014

\begin{tabular}{|c|c|c|c|c|c|c|c|c|}
\hline \multirow[b]{2}{*}{ Month } & \multirow{2}{*}{$\begin{array}{c}\text { Total } \\
\text { inpatients }\end{array}$} & \multirow{2}{*}{$\begin{array}{l}\text { Inpatients taking } \\
\text { hypnotics }\end{array}$} & \multicolumn{4}{|c|}{1 tablet } & \multirow[b]{2}{*}{2 tablets } & \multirow[b]{2}{*}{$\geq 3$ tablets } \\
\hline & & & $\begin{array}{l}\text { Zolpidem } \\
\text { IR or CR }\end{array}$ & Triazolam & $\begin{array}{c}\text { Clonazepam or } \\
\text { bromazepam }\end{array}$ & Trazodone & & \\
\hline January & 2141 & $187(8.7 \%)$ & $104(55.6 \%)$ & $10(5.3 \%)$ & $25(13.4 \%)$ & $6(3.2 \%)$ & $30(16.0 \%)$ & $12(6.4 \%)$ \\
\hline February & 1641 & $164(10.0 \%)$ & $83(50.6 \%)$ & $14(8.5 \%)$ & $38(23.2 \%)$ & $5(3.0 \%)$ & $17(10.4 \%)$ & $7(4.3 \%)$ \\
\hline March & 1976 & $184(9.3 \%)$ & $92(50.0 \%)$ & $12(6.5 \%)$ & $37(20.1 \%)$ & $9(4.9 \%)$ & $28(15.2 \%)$ & $6(3.3 \%)$ \\
\hline April & 2354 & $175(7.4 \%)$ & $92(52.6 \%)$ & $20(11.4 \%)$ & $23(13.1 \%)$ & $4(2.3 \%)$ & $28(16.0 \%)$ & $8(4.6 \%)$ \\
\hline May & 2146 & $171(8.0 \%)$ & $91(53.2 \%)$ & $16(9.4 \%)$ & $23(13.5 \%)$ & $9(5.3 \%)$ & $23(13.5 \%)$ & $9(5.3 \%)$ \\
\hline June & 2159 & $163(7.5 \%)$ & $86(52.8 \%)$ & $9(5.5 \%)$ & $42(25.8 \%)$ & $3(1.8 \%)$ & $18(11.0 \%)$ & $5(3.1 \%)$ \\
\hline July & 2408 & $175(7.3 \%)$ & $82(46.9 \%)$ & $17(9.7 \%)$ & $41(23.4 \%)$ & $8(4.6 \%)$ & $25(14.3 \%)$ & $2(1.1 \%)$ \\
\hline August & 2267 & $172(7.6 \%)$ & $78(45.3 \%)$ & $9(5.2 \%)$ & $32(18.6 \%)$ & $5(2.9 \%)$ & $38(22.1 \%)$ & $10(5.8 \%)$ \\
\hline September & 2340 & $208(8.9 \%)$ & $89(42.8 \%)$ & $28(13.5 \%)$ & $39(18.8 \%)$ & $12(5.8 \%)$ & $35(16.8 \%)$ & $5(2.4 \%)$ \\
\hline October & 2396 & $190(7.9 \%)$ & $92(48.4 \%)$ & $12(6.3 \%)$ & $41(21.6 \%)$ & $6(3.2 \%)$ & $29(15.3 \%)$ & $10(5.3 \%)$ \\
\hline November & 2201 & $183(8.3 \%)$ & $92(50.3 \%)$ & $11(6.0 \%)$ & $38(20.8 \%)$ & $7(3.8 \%)$ & $30(16.4 \%)$ & $5(2.7 \%)$ \\
\hline December & 2250 & $164(7.3 \%)$ & $83(50.6 \%)$ & $13(7.9 \%)$ & $21(12.8 \%)$ & $6(3.7 \%)$ & $30(18.3 \%)$ & $11(6.7 \%)$ \\
\hline
\end{tabular}

IR: immediate-release, CR: extended-release.

\section{DISCUSSION}

In our present study, we observed that $3.54 \%$ of inpatients took sleeping pills at the time of admission and $3.93 \%$ at the time of discharge. A total of 2256 inpatients (1.90\%) per year newly began taking sleeping pills during their hospital stay. In addition, we found that $7.3-10.0 \%$ of inpatients in an adult care unit were prescribed hypnotics. Previous studies have also reported higher hypnotics prescription rates among hospitalized patients compared to the general population. ${ }^{35,36}$ Gillis et al. ${ }^{35}$ reported that $26.2 \%$ of inpatients were prescribed hypnotics during a 2-month period of hospitalization, and one third of patients who were not previously taking sleeping pills were prescribed hypnotics at discharge. Somers et al. ${ }^{36}$ showed that $33.1 \%$ of patients were prescribed hypnotics during hospitalization. These results, as well as the results of our current study, indicate that the hypnotics prescription rate increases with hospital stay.

Hospitalized patients usually spend most of their time lying in bed during the daytime due to immobility, medical or neurological disease, pain, or mental disorders including depression or anxiety. ${ }^{3,11-13,15,16}$ Excessive time in bed can influence daily activity and subsequently cause sleep disturbance at night. In South Korea, many hospitals utilize 6-bed rooms. Compared to single-bed rooms, they can provide a noisy, crowded, and impersonal environment that may hinder sleep. ${ }^{9,10}$ Additionally, turning off the light in the evening can affect patient sleep. Sleep onset and wake up times differ among patients; however, the lights are turned off at a fixed time in the hospital (usually around 9:30-10:00 pm in the evening). Inpatients with sleep disturbance would therefore spend time lying in bed awake, which can fur- ther aggravate sleep disturbance. In other words, sleep restriction or stimulus control strategies of Cognitive-Behavioral Therapy cannot be easily applied to hospitalized patients.

The timing of sleeping pill ingestion may also affect sleep quality. Physicians usually instruct hospitalized patients to take their sleeping pills as "HS", which is 9:00 pm in most hospitals in South Korea. We previously reported that patients who were satisfied with their benzodiazepine or non-benzodiazepine gamma amino-butyric acid (GABA) agonist sleeping pills tended to take sleeping pills at an average 11:11 pm, while patients who were not satisfied with their sleeping pills tended to take sleeping pills at an average 9:16 pm. ${ }^{37}$ Based on this previous finding, the effectiveness of sleeping pills may be lower when taken too early, such as around 9:00 pm according to doctors' "HS" order. Therefore, individualized sleeping pills prescription in terms of ingestion time is needed to increase patients' satisfaction to sleeping pills. However, personalized hypnotics prescription is not commonly employed among physicians who were not familiar with sleep medicine.

Education and systemic evolution for sleep hygiene and proper sleeping pills prescription are needed to decrease the proportion of inpatients who are taking sleeping pills. Studies have reported the effectiveness of sleep programs for hospitalized patients. ${ }^{32-34}$ Previously, we applied a sleep program for psychiatric inpatients, which resulted in significant reduction in the sleeping pills prescription rate. ${ }^{32}$ We also initiated a sleep hygiene education and sleeping pills reduction program for all inpatients in the general hospital. ${ }^{38}$ This program consists of 1 ) the inclusion of a sleep hygiene leaflet in the inpatient guidebook, 2) repeated broadcasts of sleep hygiene promotion ads over the in-house broadcasting system, 3) placement of nurses especially trained in sleep hygiene in each ward, 4) continuous 
education of medical residents, and 5) posters with QR codes linked to sleep hygiene education clips. While analyses on the effects of this program are ongoing, we believe that this program may improve the environment around prescription of sleeping pills.

This study has several limitations that should be considered when interpreting and generalizing the results. First, we estimated hypnotics prescription rate at only two time points (admission and discharge), which means that it is unclear whether patients were newly diagnosed with insomnia during hospitalization or had been taking sleeping pills prior to admission for multiple other reasons. In addition, we have no information on how frequently patients took sleeping pills during the period of hospitalization. Second, physical or psychological conditions that may affect patient sleep were not assessed. Therefore, the effect of hospitalization on the use of hypnotics could not be determined within our data. Third, due to lack of information on the reason why the physician prescribed the medication, we defined hypnotics as triazolam, non-benzodiazepine GABA agonist (zolpidem and zolpidem CR), trazodone, and benzodiazepine such as bromazepam and clonazepam. In the case of Z-class drugs, only zolpidem was included because it is the only available Z-class drug in South Korea. Other medications such as several tricyclic antidepressants, antipsychotics, and prolonged release melatonin, which were not considered in the present study, have also been prescribed at night to manage sleep problems in this country. If those medications had been included as sleeping pills, the hypnotics prescription rate would have definitely been higher. In addition, while benzodiazepine can be used as a sleeping pill, it is also sometimes prescribed for anxiety disorder, movement disorder, or specific sleep disorders such as restless leg syndrome, periodic limb movement disorder, or non-rapid eye movement (REM) parasomnias or REM sleep behavior disorder. We did not differentiate between the uses of benzodiazepine, and this likely influenced our results.

To summarize, despite the limitations of this study, we have shown that the prescription rate was high among inpatients in a large general hospital in South Korea that admits 160000 inpatients per year. Hospital stay may increase the administration rate of sleeping pills in hospitalized patients. Physicians should focus on addressing the patient's sleep problem and to improve the hospital environment for patient sleep.

\section{Conflicts of Interest}

The authors have no financial conflicts of interest.

\section{REFERENCES}

1. Shapiro CM, Devins GM, Hussain MR. ABC of sleep disorders. Sleep problems in patients with medical illness. BMJ 1993;306:1532-5.

2. Henoch I, Sawatzky R, Falk H, Fridh I, Jakobsson Ung E, Sarenmalm EK, et al. Symptom distress profiles in hospitalized patients in Sweden: a cross-sectional study. Res Nurs Health 2014;37:512-23.

3. Venkateshiah SB, Collop NA. Sleep and sleep disorders in the hospital. Chest 2012;141:1337-45.
4. Meyer TJ, Eveloff SE, Bauer MS, Schwartz WA, Hill NS, Millman RP. Adverse environmental conditions in the respiratory and medical ICU settings. Chest 1994;105:1211-6.

5. Celik S, Oztekin D, Akyolcu N, Isssever H. Sleep disturbance: the patient care activities applied at the night shift in the intensive care unit. $J$ Clin Nurs 2005;14:102-6.

6. Tamburri LM, DiBrienza R, Zozula R, Redeker NS. Nocturnal care interactions with patients in critical care units. Am J Crit Care 2004;13:10212; quiz 114-5.

7. Konkani A, Oakley B. Noise in hospital intensive care units--a critical review of a critical topic. J Crit Care 2012;27:522.e1-9.

8. Park MJ, Yoo JH, Cho BW, Kim KT, Jeong WC, Ha M. Noise in hospital rooms and sleep disturbance in hospitalized medical patients. Environ Health Toxicol 2014;29:e2014006.

9. Persson E, Anderberg P, Ekwall AK. A room of one's own--Being cared for in a hospital with a single-bed room design. Scand J Caring Sci 2015; 29:340-6.

10. van de Glind I, de Roode S, Goossensen A. Do patients in hospitals benefit from single rooms? A literature review. Health Policy 2007;84:153-61.

11. Young JS, Bourgeois JA, Hilty DM, Hardin KA. Sleep in hospitalized medical patients, part 1: factors affecting sleep. J Hosp Med 2008;3:473-82.

12. Reid E. Factors affecting how patients sleep in the hospital environment. Br J Nurs 2001;10:912-5.

13. Bernhofer EI, Higgins PA, Daly BJ, Burant CJ, Hornick TR. Hospital lighting and its association with sleep, mood and pain in medical inpatients. J Adv Nurs 2014;70:1164-73.

14. Dijkstra K, Pieterse M, Pruyn A. Physical environmental stimuli that turn healthcare facilities into healing environments through psychologically mediated effects: systematic review. J Adv Nurs 2006;56:166-81.

15. Tang NK, Salkovskis PM, Hodges A, Wright KJ, Hanna M, Hester J. Effects of mood on pain responses and pain tolerance: an experimental study in chronic back pain patients. Pain 2008;138:392-401.

16. Villemure C, Bushnell MC. Mood influences supraspinal pain processing separately from attention. J Neurosci 2009;29:705-15.

17. Arora VM, Chang KL, Fazal AZ, Staisiunas PG, Meltzer DO, Zee PC, et al. Objective sleep duration and quality in hospitalized older adults: associations with blood pressure and mood. J Am Geriatr Soc 2011;59: 2185-6.

18. Parsons EC, Hough CL, Vitiello MV, Zatzick D, Davydow DS. Insomnia is associated with quality of life impairment in medical-surgical intensive care unit survivors. Heart Lung 2015;44:89-94.

19. Dean GE, Abu Sabbah E, Yingrengreung S, Ziegler P, Chen H, Steinbrenner LM, et al. Sleeping with the enemy: sleep and quality of life in patients with lung cancer. Cancer Nurs 2015;38:60-70.

20. Ohayon MM, Lader MH. Use of psychotropic medication in the general population of France, Germany, Italy, and the United Kingdom. $J$ Clin Psychiatry 2002;63:817-25.

21. Bertisch SM, Herzig SJ, Winkelman JW, Buettner C. National use of prescription medications for insomnia: NHANES 1999-2010. Sleep 2014; 37:343-9.

22. Chung S, Park B, Yi K, Lee J. Pattern of hypnotic drug prescription in South Korea: health insurance review and assessment service national patients sample. Sleep Med Res 2013;4:51-5.

23. Enomoto M, Tsutsui T, Higashino S, Otaga M, Higuchi S, Aritake S, et al. Sleep-related problems and use of hypnotics in inpatients of acute hospital wards. Gen Hosp Psychiatry 2010;32:276-83.

24. Swainston Harrison T, Keating GM. Zolpidem: a review of its use in the management of insomnia. CNS Drugs 2005;19:65-89.

25. Troy SM, Lucki I, Unruh MA, Cevallos WH, Leister CA, Martin PT, et al. Comparison of the effects of zaleplon, zolpidem, and triazolam on memory, learning, and psychomotor performance. J Clin Psychopharmacol 2000;20:328-37.

26. Finkle WD, Der JS, Greenland S, Adams JL, Ridgeway G, Blaschke T, et al. Risk of fractures requiring hospitalization after an initial prescription for zolpidem, alprazolam, lorazepam, or diazepam in older adults. J Am 
Geriatr Soc 2011;59:1883-90.

27. Neutel CI, Hirdes JP, Maxwell CJ, Patten SB. New evidence on benzodiazepine use and falls: the time factor. Age Ageing 1996;25:273-8.

28. Hajak G, Müller WE, Wittchen HU, Pittrow D, Kirch W. Abuse and dependence potential for the non-benzodiazepine hypnotics zolpidem and zopiclone: a review of case reports and epidemiological data. Addiction 2003;98:1371-8.

29. Aragona M. Abuse, dependence, and epileptic seizures after zolpidem withdrawal: review and case report. Clin Neuropharmacol 2000;23:281-3.

30. Neutel CI, Maxwell CJ. The benzodiazepine treadmill--does one prescription lead to more? Pharmacoepidemiol Drug Saf 1996;5:39-42.

31. Hallström C. Benzodiazepine dependence: Avoidance and withdrawal. Int J Psychiatry Clin Pract 1998;2:31-4.

32. Youn S, Son JI, Chung S. Preliminary results of sleep pill reduction program for psychiatric inpatients. Korean J Sleep Med 2010;12:19-22.

33. Lareau R, Benson L, Watcharotone K, Manguba G. Examining the fea- sibility of implementing specific nursing interventions to promote sleep in hospitalized elderly patients. Geriatr Nurs 2008;29:197-206.

34. McDowell JA, Mion LC, Lydon TJ, Inouye SK. A nonpharmacologic sleep protocol for hospitalized older patients. J Am Geriatr Soc 1998;46: 700-5.

35. Gillis CM, Poyant JO, Degrado JR, Ye L, Anger KE, Owens RL. Inpatient pharmacological sleep aid utilization is common at a tertiary medical center. J Hosp Med 2014;9:652-7.

36. Somers A, Robays H, Audenaert K, Van Maele G, Bogaert M, Petrovic $M$. The use of hypnosedative drugs in a university hospital: has anything changed in 10 years? Eur J Clin Pharmacol 2011;67:723-9.

37. Chung S, Youn S, Yi K, Park B, Lee S. Sleeping pill administration time and patient subjective satisfaction. J Clin Sleep Med 2016;12:57-62.

38. Youn S, Yi K, Park B, Lee S, Jung YS, Choi JS, et al. Development of sleep-hygiene education and sleeping pills reduction program for hospitalized patients. Korean J Sleep Med 2015;17:33-42. 